\title{
Neutralizing anti-drug antibodies in Fabry disease have no obvious clinical impact?
}

\author{
Malte Lenders ${ }^{1 *}$, Boris Schmitz ${ }^{2}$, Stefan-Martin Brand ${ }^{2}$ and Eva Brand ${ }^{1}$
}

\begin{abstract}
Fabry disease (FD) is a rare X-linked disorder caused by a deficiency of lysosomal a-galactosidase A activity. Treatment with recombinant enzyme replacement therapy is available since 2001 and the effects of anti-drug antibodies (ADA) on therapy efficacy and disease outcome in affected patients have been controversially reported. In this letter we discuss the importance of adequate measurements of neutralizing ADAs and appropriate longitudinal analysis to determine therapy efficiency and clinical outcome in patients with FD.
\end{abstract}

Keywords: Enzyme replacement therapy, Longitudinal, Prospective

\section{Letter to the editor}

With great interest we read the recent paper by Mauhin and colleagues entitled "Deep characterization of the anti-drug antibodies developed in Fabry disease patients, a prospective analysis from the French multicenter cohort FFABRY" [1]. The authors presented a detailed characterization of anti-drug antibodies (ADAs) in patients with Fabry disease, confirmed their frequency of $40 \%$ in men treated with agalsidase and complete cross reactivity against agalsidase alfa and beta and an unambiguous association with lyso-Gb3 considered as a hallmark of disease severity [1]. Nevertheless, they came to the conclusion that "anti-agalsidase antibodies have no obvious clinical impact". By using IgG isotype-specific ELISA-techniques, the authors demonstrated the humoral IgG-dependent response to ERT. They investigated the associations between IgG subtypes and neutralizing activity, and showed that IgG1, IgG2 and IgG4 subtypes were capable of ERT neutralization in vitro. In our opinion to further substantiate these associations it would have been mandatory to use purified IgG subtypes from patients' sera and test these fractions separately for ERT neutralization as recently demonstrated for IgG4 [2]. This approach would also have been important since it is known that not all ADAs possess neutralizing activity. Thus, ELISA-based determination of an ADA-positive status is

\footnotetext{
* Correspondence: Malte.Lenders@ukmuenster.de

${ }^{1}$ Internal Medicine D, Department of Nephrology, Hypertension and Rheumatology, University Hospital Muenster, Albert-Schweitzer-Campus 1 , D-48149 Muenster, Germany

Full list of author information is available at the end of the article
}

not sufficient to define the clinically relevant impact of ERT neutralization. Of note, the clinical use of neutralization assays to assess the effect of ADAs on clinical and biochemical outcome has repeatedly been demonstrated during the last 15 years [2-6]. Future studies need to be performed to analyze a potential impact of neutralizing and non-neutralizing ADAs on endothelial ERT-uptake.

Furthermore, we agree with Mauhin et al. that the presence of planted ERT-ADA immune complexes in kidneys as reported for other lysosomal storage disease (LSDs) [7-9] has not been addressed adequately in recent studies and needs further attention [1]. From the biochemical sight of view the formation of these complexes is probably a rare event, since according to the precipitation curve (Heidelberger curve) of antigenantibody interaction large non-soluble immune complexes will form when antigens and antibodies are in a balanced state.

In a recent prospective study including longitudinal data, a significant 2.8-fold increased risk for the formation of neutralizing ADA in male patients with FD when treated with agalsidase-beta $(1.0 \mathrm{mg} / \mathrm{kg}$ every other week) compared to agalsidase-alfa $(0.2 \mathrm{mg} / \mathrm{kg}$ every other week) was demonstrated [10]. A subgroup analysis of these patients with neutralizing ADAs also revealed a better biochemical response to agalsidase-beta at $1.0 \mathrm{mg} / \mathrm{kg}$ in terms of decreasing lyso-Gb3 levels over time [10]. To this respect, we recently demonstrated that antibodies can be saturated and appropriate enzyme dosages can overcome ADA titers during infusions (antigen 
excess), which resulted in decreased plasma lyso-Gb3 levels [2]. In their cohort, Mauhin and colleagues [1] found no differences between antibody-positive and antibody-negative in non-renal-transplanted patients. Of note, these data are difficult to interpret since the neutralizing impact of the antibodies was not considered, individual slopes were not calculated (only one time-point), and patients with severe renal impairment were excluded from the analysis. The latter point is of specific interest since antibody-positive compared to -negative patients presented with a significantly higher frequency for dialysis and renal transplantation (6 [33.3\%] vs 1 [3.7\%]; $p=0.012$ ) [1].

Moreover, significantly more antibody-positive patients were treated with agalsidase-beta $(n=14 ; 77.8 \%)$ than with agalsidase-alfa $(n=4 ; 22.2 \% ; p=0.0012)$ [1]. In combination with the missing information on ERTneutralization status, the 5-fold higher dosage due to agalsidase-beta treatment might have led to the observed effect in that no clinical differences between patients with and without ADAs had been observed.

Therefore, we conclude that neutralizing ADAs affect clinical outcomes and independent of the general assay used for neutralizing ADA measurements and titer determination, the adequate longitudinal analysis of the impact of ADAs on therapy efficiency and clinical outcome in patients with FD can only be performed when analyzed patients are stratified according to supersaturated ADA titers during infusion.

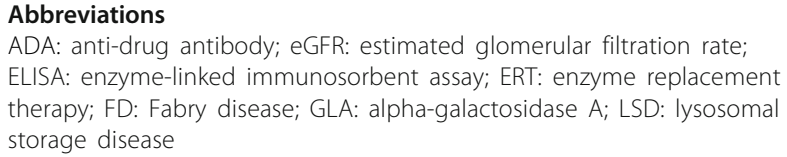

ADA: anti-drug antibody; eGFR: estimated glomerular filtration rate; ELISA: enzyme-linked immunosorbent assay; ERT: enzyme replacement therapy; FD: Fabry disease; GLA: alpha-galactosidase A; LSD: Iysosomal storage disease

\section{Acknowledgements}

We acknowledge support by the Deutsche Forschungsgemeinschaft and Open Access Publication Fund of the University of Muenster.

\section{Funding}

There was no specific funding for this manuscript.

\section{Availability of data and materials}

Data sharing not applicable to this article as no datasets were generated or analyzed during the current study.

\section{Authors' contributions}

All authors contributed equally, ML, BS: design, literature search, discussion, first Draft; SMB, EB: literature search, discussion, critical comments. All authors read and approved the final manuscript.

\section{Ethics approval and consent to participate}

Not applicable.

\section{Consent for publication}

Not applicable.

\section{Competing interests}

$M L$ received speaker honoraria, travel funding and research grants from Sanofi, Shire, and Amicus Therapeutics. EB received research grants and speaker honoraria from Sanofi, Shire, and Amicus Therapeutics. SMB received speaker honoraria and research grants from Shire. BS has nothing to declare.

\section{Publisher's Note}

Springer Nature remains neutral with regard to jurisdictional claims in published maps and institutional affiliations.

\section{Author details}

${ }^{1}$ Internal Medicine D, Department of Nephrology, Hypertension and Rheumatology, University Hospital Muenster, Albert-Schweitzer-Campus 1, D-48149 Muenster, Germany. ${ }^{2}$ Institute of Sports Medicine, Molecular Genetics of Cardiovascular Disease, University Hospital Muenster, Muenster, Germany.

Received: 27 August 2018 Accepted: 21 September 2018

Published online: 29 September 2018

References

1. Mauhin W, Lidove O, Amelin D, Lamari F, Caillaud C, Mingozzi F, et al. Deep characterization of the anti-drug antibodies developed in Fabry disease patients, a prospective analysis from the French multicenter cohort FFABRY Orphanet J Rare Dis. 2018;13:127.

2. Lenders M, Schmitz B, Brand SM, Foell D, Brand E. Characterization of drug-neutralizing antibodies in patients with Fabry disease during infusion. J Allergy Clin Immunol. 2018;141:2289-92.

3. Linthorst GE, Hollak CE, Donker-Koopman WE, Strijland A, Aerts JM. Enzyme therapy for Fabry disease: neutralizing antibodies toward agalsidase alpha and beta. Kidney Int. 2004;66:1589-95.

4. Aerts JM, Groener JE, Kuiper S, Donker-Koopman WE, Strijland A, Ottenhoff $\mathrm{R}$, et al. Elevated globotriaosylsphingosine is a hallmark of Fabry disease. Proc Natl Acad Sci U S A. 2008:105:2812-7.

5. Rombach SM, Aerts JM, Poorthuis BJ, Groener JE, Donker-Koopman W, Hendriks $\mathrm{E}$, et al. Long-term effect of antibodies against infused alphagalactosidase a in Fabry disease on plasma and urinary (lyso)Gb3 reduction and treatment outcome. PLoS One. 2012; e47805:7.

6. Lenders M, Stypmann J, Duning T, Schmitz B, Brand SM, Brand E. Serummediated inhibition of enzyme replacement therapy in Fabry disease. J Am Soc Nephrol. 2016;27:256-64

7. Hunley TE. Corzo D, DudekM, Kishnani P, Amalfitano a, Vhen YT, et al. Nephrotic syndrome complicating alpha-glucosidase replacement therapy for Pompe disease. Pediatrics. 2004;1 14:e532-e5.

8. Debiec H, Valayannopoulos V, Boyer O, Nöel LH, Callard P, Sarda H, et al. Allo-immune membranous nephropathy and recombinant aryl sulfatase replacement therapy: a need for tolerance induction therapy. J Am Soc Nephrol. 2014;25:675-80

9. Ronco P, Cebiec H. Pathophysical advances in membranous nephropathy: time for a shift in patient's care. Lancet. 2015;385:1983-92.

10. Arends M, Biegstraaten M, Wanner C, Sirrs S, Mehta A, Elliott PM, et al. Agalsidase alfa versus agalsidase beta for the treatment of Fabry disease: an international cohort study. J Med Genet. 2018;55:351-8.
Ready to submit your research? Choose BMC and benefit from:
- fast, convenient online submission
- thorough peer review by experienced researchers in your field
- rapid publication on acceptance
- support for research data, including large and complex data types
- gold Open Access which fosters wider collaboration and increased citations
- maximum visibility for your research: over $100 \mathrm{M}$ website views per year
At BMC, research is always in progress.
Learn more biomedcentral.com/submission 